\title{
Storm surge risk mitigation under ambiguity by coupled tropical cyclone and decision model
}

\author{
Toshio Fujimi ( $\nabla$ fujimi.toshio.7x@kyoto-u.ac.jp ) \\ Kyoto University https://orcid.org/0000-0001-7197-0336
}

\section{$\mathrm{Ha} \mathrm{Si}$}

Kyoto University

\section{Xinyu Jiang}

Wuhan University of Technology

Nobuhito Mori

Kyoto University https://orcid.org/0000-0001-9082-3235

\section{Rawshan Begum}

Universiti Kebangsaan Malaysia

Masahide Watanabe

Ryukoku University

Hirokazu Tatano

Kyoto University https://orcid.org/0000-0001-7209-4358

\section{Eiichi Nakakita}

Kyoto University

\section{Article}

Keywords: storm surge, risk mitigation, environmental policy, ambiguity premium

Posted Date: October 12th, 2021

DOI: https://doi.org/10.21203/rs.3.rs-934019/v1

License: (c) (i) This work is licensed under a Creative Commons Attribution 4.0 International License.

Read Full License 
Storm surge risk mitigation under ambiguity by coupled tropical cyclone and decision model 
Even as storm surge risks are increasing, the projections of such risks have an element of ambiguity. Consequently, policymakers find it extremely difficult to design policies to deal with storm surge risks. Therefore, in this study, we have linked the tropical cyclone models and stated preference experiments with decision models to provide a fresh perspective on households' preferences for storm surge risk mitigation under ambiguity. We have validated households' choices under the average and worst projections of storm surges and estimated the expected loss reduction, risk premium, and ambiguity premium for storm surge risk mitigation. Our study reveals that households pay disproportionately more attention to the worst case and that the ambiguity premium is not negligible. This leads to an important conclusion that policymakers should factor in the ambiguity premium to formulate risk mitigation policies.

According to IPCC's recent report, in coastal cities, the combination of more frequent extreme sea level events (due to sea level rise and storm surge) and extreme rainfall/river flow events will make flooding more probable. ${ }^{1}$ Indeed, climate change and global warming pose an increasing threat to coastal flood risks from tropical cyclone and storm surge. ${ }^{2-10}$ Moreover, the projected upsurge intensity and frequency of extreme sea levels for the coming decades increases the risk of catastrophic losses, ${ }^{11}$ hence, both structural for example dike construction, and non-structural (education and awareness, insurance, social safety net etc.) measures are essential as coastal defense. Instead, the scientific projection of storm surge risks inevitably involves uncertainty due to the stochastic nature of extreme events and unknowns or limited knowledge about the mechanism of 
tropical cyclones or typhoons, the rates and magnitudes of sea level rise, and model parameter values. ${ }^{8,12-15}$ The projections of storm surge risks include ambiguity (uncertainty about probabilities), posing significant challenges for risk reduction or mitigation policies, such as rising dikes, building code restrictions, land use restrictions, and flood insurances. Uncertainty can be classified into "aleatory uncertainty" and "epistemic or deep uncertainty." 16,17 The aleatory uncertainty refers to natural randomness of the relevant event, whereas epistemic uncertainty is the situation where there is hardly any information to specify a single probability density function (PDF). In the context of storm surge, epistemic uncertainty may arise due to a lack of sufficient knowledge and data on typhoon systems such as cyclogenesis factors, developmental processes, and their movement. In economics, aleatory uncertainty is classified as "risk" and epistemic uncertainty corresponds to "ambiguity." 18,19 While risk is represented by a single well-defined PDF, ambiguity often denotes multiple PDFs derived from different models with various parameter settings. ${ }^{17,20}$ Ambiguity (here, multiple projected PDFs) of storm surge risk makes it difficult to formulate risk mitigation policies, ${ }^{21,22}$ which motivates to conduct our unique analysis of coupled tropical cyclone and decision models. The common approach using average projection of multiple predictions ${ }^{23-28}$ can be straightforward, but it may lead to ignoring the possibility of worst-case occurrences. Instead, the worst projections, such as probable maximum flood ${ }^{29}$ and plausible worstcase estimate, ${ }^{30,31}$ are often considered in flood risk management. Although a risk mitigation policy designed for the worst projection performs to tackle most inundation risks, the potential cost of 
implementing the policy remains a challenge. ${ }^{7,11}$ Thus, policymakers face difficulty on how to use the multiple projections for risk mitigation policies. This problem is particularly acute when designing structural flood mitigation measures, such as dikes or sea walls to prevent flood damage only from storm surges with predefined design levels (e.g., a 100-year storm surge) or less, so that their effect might be quite different between average and worst projections. ${ }^{20}$ Suppose that areas A and B face $1 \mathrm{~m}$ (meter) and $2 \mathrm{~m}$ storm surges in the average projection, and $3 \mathrm{~m}$ and $4 \mathrm{~m}$ storm surges in the worst projection, respectively. A dike with a $3 \mathrm{~m}$ height can protect both areas in the average projection but cannot protect area $\mathrm{B}$ in the worst projection. Therefore, it is crucial to emphasize the importance of geographical conditions and distributions in evaluating the risk mitigation effects of the structural measures under multiple projections.

In this regard, policy makers' judgement should reflect the preferences of stakeholders for risk and ambiguity and the extent to which they plan to allocate resources for protection against the worst projection. ${ }^{32,33}$ This is vital for the residential or household sectors in the coastal areas, as people's decisions are often influenced by ambiguity. ${ }^{18,19}$ Even though some studies have explored the ambiguity of storm surge risks, ${ }^{15,28,34,35}$ proposed decision support methods under ambiguity, ${ }^{21,31,36,37}$ and estimated residents' preferences to mitigate flood risks from storm surges, ${ }^{38,39,40}$ the scholars have not paid sufficient attention to ambiguity and estimation of both risk and ambiguity premiums for storm surge risk mitigation. To our knowledge, no study have investigated households' preferences in mitigating storm-surge inundation risks under ambiguity; 
therefore, in this study, we attempt to fill this gap.

Increased mean and extreme sea level, alongside ocean warming and acidification, are projected to exacerbate risks for human communities in low-lying coastal areas. ${ }^{41}$ Japan experiences huge typhoons, causing serious storm surge damages. Osaka Bay is one of the most vulnerable areas in terms of storm surge risks in Japan and is ranked fifth among the world's 120 cities in terms of expected annual losses due to storm surges in $2050 .{ }^{42}$ Recently, in 2018 , Typhoon Jebi caused 14 deaths, 1014 injuries and destroyed 686 houses in Osaka Bay. ${ }^{43}$ Thus, we assess storm surge risks and ambiguity in the coastal areas of Osaka Bay in this study. Fig. S1 and Fig. S2 show our study areas and the flow of methodological framework and analysis. Here, we briefly illustrate the steps followed for analysis (see Methods for details): i) we conduct a simulation of typhoon generations for 200 years using global stochastic tropical cyclone model (GSTCM); ${ }^{44}$ ii) the four worst typhoons are selected (after fulfilling the conditions), and the storm surges of Osaka Bay are simulated by a full-coupled surge-wave-tide coupled model (SuWAT); ${ }^{45}$ iii) we predict the inundation depth due to storm surges using the inundation simulation model; ${ }^{46,47}$ iv) by repeating step i) to iii), we get 25 PDFs of the inundation risk for each dike level: current level and rising by $0.5 \mathrm{~m}, 1.0 \mathrm{~m}, 1.5 \mathrm{~m}$, and $2.0 \mathrm{~m}(25 \times 5) ; \mathrm{v})$ the average and worst projections of the inundation risk (PDFs) are specified by each zip-code in the web-based survey; vi) we estimate households' preferences by asking them to choose whether to buy a hypothetical insurance covering all the losses due to storm surges by presenting the average and worst projections of inundation risks to their houses; vii) by using the 
choice experiment data, a decision model is applied for estimating risk and ambiguity premiums; and viii) finally, we analyze the geographical distribution of risk and ambiguity premiums by geographic information system (GIS). Fig.1 shows the average and worst projections of storm surge inundation risks (based on exceedance probability) with different dike levels in each zip-code area.

Several studies have applied the stated preference method to estimate households' preferences to reduce storm surge risks, ${ }^{38-40}$ however, our study is the first attempt to estimate households' preferences under ambiguity of storm surge risk mitigation (Fig.2). It is worth noting that the risk premium is the additional payment for avoiding random variability of the economic loss from storm surge risks. For instance, the risk premium is zero if the economic loss has no random variability (fixed amount as expected loss) or an individual's risk attitude is neutral (i.e. his/her utility function is linear). Instead, the ambiguity premium is the additional payment for avoiding multiple projections, that is, zero if a unique projection of storm surge risks is specified. We used limited degree of confidence (LDC) model to deal with the ambiguity of storm surge risks because this model is useful in designing robust strategies for dealing with the uncertainty of climate change. ${ }^{48-50}$ In addition to resolving the ambiguity of the inundation risks, this study attests to the importance of coupled stochastic tropical cyclone model and stated preference method. The details of storm surge and inundation simulation, survey procedures, and decision models are explained in the Methods section.

Table 1 reveals that the estimate of the degree of confidence in Model 1 is $0.9049(99 \%$ 
confidence interval; $0.8294,0.9804)$ with statistical significance at the $1 \%$ level. This indicates that the average household (sampled) decides about risk mitigation policy by weighting $90 \%$ of the average projection and $10 \%$ of the worst projection. If we assign equal weight to each of the 25 projections, the weight of the worst projection might be less than $4 \%(=1 / 25) * 1$. Thus, our findings show that households tend to disproportionately pay greater attention to the worst case (i.e., $10 \%$ rather than 4\%). The constant relative risk aversion (CRRA) coefficient of Model 1 is 0.3764 (99\% confidence interval; $0.4694,1.4984)$, which is statistically significant at the $1 \%$ level. Moreover, Model 2 presents the heterogeneity of households' socioeconomic attributes such as age, gender, family size and education which affects the estimated parameters of confidence of degree, $\alpha$ and CRRA coefficient, $r$. No statistically significant estimates are found at the $5 \%$ level. Thus, we decide to use the estimated results of Model 1 to calculate the risk and ambiguity premiums. Using the estimated parameters of Model 1 and the sample average of household assets (34.1 million yen), we calculate the expected loss reduction, risk premium, and ambiguity premium for full protection from the storm surge risk (for details, see Methods section). Then, each value is multiplied by the number of households in each zip-code area (Supplementary Fig. S3) and aggregated for the entire target area, as presented in Table 2. The total economic value or WTP is 1,743 million yen (about 17 million USD) for full protection insurance policy from the storm surge

*1 Technically, the worst projection is constructed as the worst envelope curve of 25 projected distribution on storm surge inundation depth. Therefore, the weight of the worst projection should be less than $4 \%$ even though we give equal weight to each of the 25 projections. 
risk under ambiguity in the target area. It consists of the expected loss reduction, risk premium, and ambiguity premium, which are 821,65 , and 849 million yen, respectively. The risk premium and ambiguity premium are $8 \%$ and $103 \%$, respectively, compared with the value of expected loss reduction for eliminating storm surge risks in the target area. Thus, the total economic value is $211 \%$ of the expected loss reduction.

In LDC model, the expected loss reduction and risk premium are calculated using the average prediction, while ambiguity premium is estimated with the worst prediction. The estimated LDC model indicates that a statistically representative household weighs $90 \%$ on the average projection and $10 \%$ on the worst projection, which apparently imply small ambiguity premium compared to the value of expected loss reduction and risk premium. However, the results demonstrate that the ambiguity premium is much larger than risk premium and almost equivalent to the expected loss reduction. This is because the asset loss based on the worst projection is much larger than the loss based on the average projection. As can be seen in Fig. 1, there are many areas where houses will be submerged or the flooding on the floor will be occurred in the worst projection, while the average prediction shows no areas of submerged houses and very small area of flooding on the floor will occur. Due to this relationship between the geographic conditions and inundation levels, the asset loss and its dispersion in the average and worst projections are very different, as shown numerically in Table S2.

Estimating the economic value of dike rise is important for the storm surge risk mitigation policies. Our study considers four dike rising policies assuming all dikes in the target area are 
uniformly raised by $0.5 \mathrm{~m}, 1.0 \mathrm{~m}, 1.5 \mathrm{~m}$ and $2.0 \mathrm{~m}$, respectively. Table 2 indicates that the total economic value of dike rising by $2.0 \mathrm{~m}$ is 1,682 million yen, which is quite close to the benefit of full protection (1,743 million yen). This implies that dike rising by $2.0 \mathrm{~m}$ can prevent almost all damages from storm surges. Further, we divided the dike rising by $2 \mathrm{~m}$ into four steps: " 0 to $0.5 \mathrm{~m}$," "0.5 to $1.0 \mathrm{~m}$," "1.0 to $1.5 \mathrm{~m}$," and " 1.5 to $2.0 \mathrm{~m}$ " and calculate their values. The results demonstrate that the marginal values of dike rising decrease with the higher level of dike rising. The expected loss reduction and risk premium for dike rising of " 0 to $0.5 \mathrm{~m}$ " are 581 and 64 million yen, which drop sharply to 110 and 1 million yen, respectively, for dike rising of " 0.5 to $1.0 \mathrm{~m}$." The ambiguity premium is about 390 million yen for dike rising of both " 0 to $0.5 \mathrm{~m}$ " and " 0.5 to $1.0 \mathrm{~m}$ " and then largely falls to 55 million yen for dike rising of " 1.0 to $1.5 \mathrm{~m}$." This is because the first dike rising by $0.5 \mathrm{~m}$ to the current level may protect the target area mostly from storm surges in the average prediction but cannot protect in the worst prediction. Additional dike rising by $0.5 \mathrm{~m}$ ( or $+1.0 \mathrm{~m}$ to the current level) can prevent storm surge inundation largely, even in the worst prediction. Thus, the marginal ambiguity premium decreases more slowly than the marginal value of the expected loss reduction and the marginal risk premium as dike rising increases.

The geographical distributions of the expected loss reduction, risk premium, and ambiguity premium provide useful information for designing effective storm surge risk mitigation policies.

Fig. 3 demonstrates that these values are disproportionately located in areas close to the rivers and the sea along the Osaka Bay, the coastal areas in Amagasaki city, Osaka city and Sakai city and the areas 
of Yodo riverside. This means that the economic value of protection from the storm surge risk mostly depends on the geographical conditions of that areas. In each step of dike rising by $0.5 \mathrm{~m}$ from 0 to $2.0 \mathrm{~m}$, the values of the expected loss reduction, risk premium, and ambiguity premium reveal different distribution patterns, indicating that the benefited areas of dike rising also depend on the baseline level of dike as well. This also stresses the need for a better understanding and robust analysis of spatial distribution patterns for designing storm surge risk mitigation policies.

Fig 3 illustrates that ambiguity premiums are narrowly distributed compared to expected loss reduction and risk premiums. Notably, in each level of dike rising by $0.5 \mathrm{~m}$ (from 0 to $2.0 \mathrm{~m}$ ), expected loss reduction occurs and risk premiums arise in the same areas while ambiguity premiums generally happen in different areas. These results suggest that decision on dike rising without considering ambiguity premium (or the worst projection) may cause a significant underestimation of dike rising value in in some areas rather than all areas with storm surge risks.

Our results provide several policy implications for mitigating storm surge risks. First, ignoring the ambiguity premium causes significant undervaluation of storm surge risk mitigation, in this case, dike rising. Our decision model of LDC finds that a statistically representative household weighs $90 \%$ on the average projection and $10 \%$ on the worst projection. Although the weight on the worst projection is not very high, it causes a large ambiguity premium that is almost equivalent to the value of the expected loss reduction for eliminating storm surge risks. This is because the economic loss due to inundation under the worst projection is much larger than the loss under the average 
projection. Thus, the total economic value of eliminating storm surge risk is almost half if the ambiguity premium is ignored.

Second, the areas that benefit from the structural mitigation measures, such as dike rising, are differently distributed depending on the geographical heterogeneity of the areas and the current level of dikes. The projection of storm surge risks and ambiguity can be largely affected by geographical conditions such as land elevation and distance from the sea or river. To ensure a predetermined safety level for all areas, policymakers should capture the geographical distribution of benefited areas. In particular, the ambiguity premiums need special attention because they are distributed differently from the expected loss reduction and risk premium. Thus, the ambiguity premium emphasizes the importance of considering geographical heterogeneity for effective risk mitigation policies.

Third, the ambiguity premium stems from households' over-concern of the worst projection, which may lead to an over-allocation of resources to prevent storm surge damage before a disaster. However, compensation for economic loss after disaster is never over-valued because this amount is independent of households' preferences for ambiguity. Hence, this study suggests that post-disaster compensation, such as public insurance, is economically effective in coping with ambiguity while continuing with pre-disaster prevention measures, such as dike rising, land use regulation, and building code. Thus, a risk mitigation policy combining public insurance for the worst projection and 
pre-disaster prevention measures, such as dike construction for average projection, can be effective and efficient approach.

This study provides a new perspective on households' preferences for storm surge risk mitigation under ambiguity coupling global stochastic tropical cyclone model and stated preference experiment with the LDC model and GIS. We estimated the values of the expected loss reduction, risk premium, and ambiguity premium for full protection from the storm surge risk, which is equal to the total economic value or WTP for full protection of an insurance policy. Our analysis indicates that ambiguity premium is not negligible size in terms of economic efficiency or cost-benefit consideration of risk mitigation policies as they are extremely distributed in some areas of higher expected loss from storm surge inundation. This suggests that ambiguity premiums should be measured for planning and implementation of storm surge risk mitigation polices. Though our results have extensive implications from many perspectives, they only address the ambiguity of storm surge risk projections rather than other sources of ambiguity such as changes of climate and residential population. Moreover, our analysis focuses on household sector, whereas other sectors are also important to be considered such as, commercial and industrial buildings, roads and subways, and human health. Future research is required for further investigation.

\section{Acknowledgements}


This work was funded by the Integrated Research Program for Advancing Climate Models

(TOUGOU Program), MLIT Research Grant for River Management Technology and JSPS

KAKENHI Grant Number JP 17K06603.

\section{Author Contributions}

T.F., H.T., and E.N. jointly conceived and designed the study. H.S., X.J., and N.M. contributed with the tropical cyclone model and storm surge inundation simulation. T.F., H.T., and M.W. carried out stated preference experiment and helped for survey design. T.F., H.T., and M.W. analyzed the data and R.A.B. provided advice on model experiments and data analysis. T.F. and R.A.B. wrote the manuscript and all the authors contributed to finalize the manuscript.

\section{Competing Interests statement:}

The authors declare no competing interests.

\section{References}

1. IPCC, 2021: Summary for Policymakers. In: Climate Change 2021: The Physical Science Basis. Contribution of Working Group I to the Sixth Assessment Report of the Intergovernmental Panel on Climate Change [Masson Delmotte, V., P. Zhai, A. Pirani, S. L. Connors, C. Péan, S. Berger, N. Caud, Y. Chen, L. Goldfarb, M. I. Gomis, M. Huang, K. Leitzell, E. Lonnoy, J. B. R. Matthews, T. 
K. Maycock, T. Waterfield, O. Yelekçi, R. Yu and B. Zhou (eds.)]. Cambridge University Press. In Press.

2. Nicholls, R. J., Hoozemans, F. M. J., \& Marchand, M. Increasing flood risk and wetland losses due to global sea-level rise: Regional and global analyses. Global Environmental Change 9, S69S87 (1999). https://doi.org/10.1016/S0959-3780(99)00019-9

3. Goldenberg, S. B., Landsea C. W., Mestas-Nunez A. M., \& Gray W. M. The recent increase in Atlantic hurricane activity: Causes and implications. Science 293, 474-479, (2001). doi:10.1126/science.1060040.

4. Emanuel, K. Increasing destructiveness of tropical cyclones over the past 30 years. Nature 436, 686-688 (2005). http://dx.doi.org/10.1038/nature03906.

5. Hansen, J. et al. Efficacy of climate forcing J. Geophys. Res. 110, D18104 (2005).

6. Smith, A. B. \& Katz, R. W. US billion-dollar weather and climate disasters: data sources, trends, accuracy, and biases. Nat. Hazards 67, 387-410 (2013). https://doi.org/10.1007/s11069-013-05665

7. Hinkel, J. et al. Coastal flood damage and adaptation costs under $21^{\text {st }}$ century sea-level rise. $P$. Natl. Acad. Sci. USA 111, 3292-3297 (2014). doi:10.1073/pnas.1222469111.

8. Little, C. M. et al. Joint projections of the US East Coast sea level and storm surge. Nat. Clim. Change 5, 1114-1120 (2015). https://doi.org/10.1038/nclimate2801.

9. Muis, S., Verlaan, M., Winsemius, H. C., Aerts, J. C. J. H., \& Ward, P. J. A global reanalysis of 
storm surges and extreme sea levels. Nat. Commun. 7, 11969 (2016).

https://doi.org/10.1038/ncomms11969

10. Marsooli, R., Lin, N., Emanuel, K., \& Feng, K. Climate change exacerbates hurricane flood hazards along the US Atlantic and gulf coasts in spatially varying patterns. Nature Communications 10, 1-9 (2019). https://doi.org/10.1038/s41467-019-11755-z

11. Vousdoukas, M. I. et al. Climatic and socioeconomic controls for future coastal flood risk in Europe. Nat. Clim. Change 8, 776-780 (2018). https://doi.org/10.1038/s41558-018-0260-4

12. Henderson-Sellers, A., et al. Tropical cyclones and global climate change. Bull. Amer. Meteor. Soc. 79, 19-38 (1998). https://doi.org/10.1175/1520-0477(1998)079<0019:TCAGCC >2.0.CO;2

13. Knutson, T. R., et al. Tropical cyclones and climate change. Nat. Geosci. 3, 157-163 (2010). https://doi.org/10.1038/ngeo779

14. Grinsted, A., Moore, J. C., \& Jevrejeva, S. Projected Atlantic hurricane surge threats from rising temperatures. Proceedings of the National Academy of Sciences of the United States of America 110, 5369-5373 (2013). https://doi.org/10.1073/pnas.1209980110.

15. Wong, T. E. \& Keller, K. Deep uncertainty surrounding coastal flood risk projections: A case study for New Orleans. Earth's Future 5, 1015-1026 (2017). https://doi.org/10.1002/2017EF000607

16. Hoffman, F. O. \& Hammonds, J. S. Propagation of uncertainty in risk assessments: the need to distinguish between uncertainty due to lack of knowledge and uncertainty due to variability. Risk 
Anal. 14, 707-712 (1994). https://doi.org/10.1111/j.1539-6924.1994.tb00281.x

17. Merz B. \& Thieken, A. H. Flood risk curves and uncertainty bounds. Nat Hazards 51, 437-458 (2009). https://doi.org/10.1007/s11069-009-9452-6

18. Camerer, C. \& Weber, M. Recent developments in modeling preferences include uncertainty and ambiguity. J. Risk Uncertain 5, 325-370 (1992). https://doi.org/10.1007/BF00122575

19. Etner, J., Jeleva, M., \& Tallon, J. M. Decision theory under ambiguity. J. Econ. Surv. 26, 234270 (2012). https://doi.org/10.1111/j.1467-6419.2010.00641.x

20. Kunreuther, H. et al. Risk management and climate change. Nat. Clim. Change 3, 447-450 (2013). https://doi.org/10.1038/nclimate1740

21. Sriver, R. L., Lempert, R. J., Wikman-Svahn, P., \& Keller, K. Characterizing uncertain sea-level rise projections to support investment decisions. PLoS ONE 13, e0190641 (2018). https://doi.org/10.1371/journal.pone.0190641.

22. Oppenheimer, M., Little, C. M., \& Cooke, R. M. Expert judgment and uncertainty quantification for climate change. Nat. Clim. Change 6, 445-451 (2016). https://doi.org/10.1038/nclimate2959.

23. Knutti, R. The end of model democracy? Clim. Change 102, 395-404 (2010). https://doi.org/10.1007/s10584-010-9800-2

24. Knutti, R., Furrer, R., Tebaldi, C., Cermak, J., \& Meehl, G. A. Challenges in combining projections from multiple climate models. J. Clim 23, 2739-2758 (2010). https://doi.org/10.1175/2009JCLI3361.1 
25. Stephenson, D. B., Collins, M., Rougier, J. C., \& Chandler, R. E. Statistical problems in the probabilistic prediction of climate change. Environmetrics 23, 364-372 (2012). DOI: 10.1002/env.2153

26. Watkiss, P., Hunt, A., \& Blyth Wand Dyszynski, J. The use of new economic decision support tools for adaptation assessment: A review of methods and applications towards guidance on applicability. Clim. Change 32, 401-16 (2015). https://doi.org/10.1007/s10584-014-1250-9

27. Boettle, M., Rybski, D., \& Kropp, J. P. Quantifying the effect of sea level rise and flood defense -A point process perspective on coastal flood damage. Nat. Hazards Earth Syst. Sci. 16, 559-76 (2016). https://doi.org/10.5194/nhess-16-559-2016

28. Oddo, P. C. et al. Deep uncertainties in sea-level rise and storm surge projections: Implications for coastal flood risk management. Risk Anal. 40, 153-168 (2020). https://doi.org/10.1111/risa.12888

29. Schwerdt, R. W., Ho, F. P., \& Watkins R.W. Meteorological criteria for standard project hurricane and probable maximum hurricane wind fields: Gulf and East coast of the United States. NOAA Tech. Rep. NWS 23, US Department of Commerce, Washington D. C. (1979).

30. Ranger N., Reeder, T., \& Lowe, J. Addressing 'deep' uncertainty over long-term climate in major infrastructure projects: Four innovations of the Thames Estuary 2100 Project. Euro. J. Decis. Process 1, 233-62 (2013). https://doi.org/10.1007/s40070-013-0014-5

31. Buchanan, M. K., Kopp, R. E., Oppenheimer, M., \& Tebaldi, C. Allowances for evolving coastal 
flood risk under uncertain local sea-level rise. Clim. Change 137, 347-362 (2016).

https://doi.org/10.1007/s10584- 016-1664-7.

32. Shrader-Frechette, K. S. Risk and Rationality: Philosophical foundations for populist reforms (University of California Press, Berkeley, 1997).

33. Downton M. W., Morss R. E., Wilhelmi O. V., Gruntfest E., \& Higgings M. L. Interactions between scientific uncertainty and flood management decisions: Two case studies in Colorado. Environ Hazards 6, 134-146 (2005). https://doi.org/10.1016/j.hazards.2006.05.003

34. Hallegatte, S. et al. Assessing climate change impacts, sea level rise, and storm surge risk in port cities: A case study on Copenhagen. Clim. Change 104, 113-137. https://doi.org/10.1007/s10584010-9978-3

35. Resio, D. T., Irish, J. L., Westerink, J. J., \& Powell, N. J. The effect of uncertainty on estimates of hurricane surge hazards. Nat. Hazards, 66, 1443-1459 (2013). DOI 10.1007/s11069-012-0315-1

36. Hunter, J. A simple technique for estimating an allowance for uncertain sea-level rise. Clim. Change 113, 239-252 (2012). https://doi.org/10.1007/s10584-011-0332-1.

37. Rohmer, J., Cozannet, G. L., \& Manceau, J. C., Addressing ambiguity in probabilistic assessments of future coastal flooding using possibility distributions. Clim. Change 155, 95-109 (2019). https://doi.org/10.1007/s10584-019-02443-4.

38. Botzen, W. J., Aerts, J. C., \& van den Bergh, J. C. Willingness of homeowners to mitigate climate risks through insurance. Ecol. Econ. 68, 2265-2277 (2009). 
https://doi.org/10.1016/j.ecolecon.2009.02.019

39. Botzen, W. J. W., \& van den Bergh, J. C. J. M. Monetary valuation of insurance against flood risk under climate change. International Economic Review 53, 1005-1025 (2012).

https://www.jstor.org/stable/23251505

40. Withey, P., Sullivan, D., \& Lantz, V. Willingness to pay for protection from storm surge damages under climate change in Halifax Regional Municipality. J. Environ. Manage. 241, 44-52 (2019). https://doi.org/10.1016/j.jenvman.2019.04.007

41. IPCC, 2019: Summary for Policymakers. In: IPCC Special Report on the Ocean and Cryosphere in a Changing Climate [H.-O. Pörtner, D.C. Roberts, V. Masson-Delmotte, P. Zhai, M. Tignor, E. Poloczanska, K. Mintenbeck, A. Alegría, M. Nicolai, A. Okem, J. Petzold, B. Rama, N.M. Weyer (eds.)]. In press.

42. Abadie, L. M., Galarraga, I., \& de Murieta, E. S. Understanding risks in the light of uncertainty: low-probability, high-impact coastal events in cities. Environ. Res. Lett. 12, 14017 (2017). https://doi.org/10.1088/1748-9326/aa5254.

43. Japan Meteorological Agency. (2015). Knowing sea and going with sea: Preparation for storm surges. Accessed on https://www.jma.go.jp/jma/kishou/books/takashiotakanami/index.html.

44. Nakajo, S., Mori, N., Yasuda, T., \& Mase, H. Global stochastic tropical cyclone model based on principal component analysis with cluster analysis. J. Appl. Meteorol. Climatol. 53, 1547-1577 (2014). https://doi.org/10.1175/JAMC-D-13-08.1 
45. Kim, S. Y., Yasuda, T., \& Mase, H. Numerical analysis of effects of tidal variations on storm surges and waves. Appl. Ocean Res. 30, 311-322 (2008). https://doi.org/10.1016/j.apor.2009.02.003

46. Liang Q. Flood simulation using a well-balanced shallow flow model. J. Hydraul. Eng. 136, 669-675 (2010). https://doi.org/10.1061/(ASCE)HY.1943-7900.0000219

47. Jiang, X., Mori, N., Tatano, H., \& Yang, L. Simulation-based exceedance probability curves to assess economic impacts of storm surge inundation under climate change scenarios: A case study in Ise Bay, Japan. Sustainability 11, 1090 (2019). https://doi.org/10.3390/su11041090

48. Lange, A. Climate change and the irreversibility effect combining expected utility and maximin. Environ. Resour. Econ. 25, 417-434 (2003). https://doi.org/10.1023/A:1025054716419

49. Froyn, C. B. Decision criteria, scientific uncertainty, and the global warming controversy. Mitig. Adapt. Strateg. Glob. Chang. 10,183-211 (2005). https://doi.org/10.1007/s11027-005-3782-9

50. McInerney, D., Lempert, R., \& Keller, K. What are robust strategies in the face of uncertain climate threshold responses? Clim. Change 112, 547-568 (2012). https://doi.org/10.1007/s10584011-0377-1 


\section{Methods}

Typhoon simulation. To predict the storm surge risk in Osaka Bay, we have conducted typhoon simulations using GSTCM. ${ }^{44}$ An extreme storm surge occurs due to the combination of intense tropical cyclones, dangerous tracks and fast-moving speeds. As such a combination does not occur often, extreme surges rarely occur. Numerous simulated typhoons are required to predict storm surge risks in a particular region. Using the global circulation model (GCM) is one of choices, but the typhoons in the GCMs have a large bias, and the length of the simulation period is insufficient for analyzing extreme storm surge events. A stochastic tropical cyclone model (STCM) is often used to increase the number of simulated typhoons with different parameter values such as track/direction, minimum sea level pressure, and translation speed based on Monte Carlo simulations. Among several approaches of STCMs, GSTCM takes the translation model approach developed by Emanuel et al. ${ }^{51}$ and Rumpf et al., ${ }^{52}$ where typhoon parameters are sequentially determined by using PDFs of their rates of change estimated from the given data, which allows more flexibility in rates of change than the other approaches. Unlike other STCMs that were developed for specific ocean basins, GSTCM was expanded to implement annual global simulation of tropical cyclones, which is necessary for assessing climate change factors. To project the storm surge risks under the current climatic conditions, we have calibrated the parameters of the GSTCM using data from the International Best Track Archive for Climate Stewardship (IBTrACS) provided by the National Oceanic and Atmospheric Administration. 
Inundation simulation from storm surges. This study conducts typhoon simulations over 200 years by using GSTCM under the current climate conditions and selects the worst four typhoons among simulated typhoons satisfying the following three conditions: (i) the minimum distance to Osaka Bay is less than $200 \mathrm{~km}$, (ii) the minimum central pressure is less than $950 \mathrm{hPa}$, and (iii) the velocity of the typhoon at landfall is higher than $20 \mathrm{~km} / \mathrm{h}$. Then, by adding inputs like the simulated properties (track, speed, and central pressure) of the four selected typhoons, storm surges in Osaka Bay are simulated using the SuWAT. ${ }^{45}$ The model simulates storm surge heights as well as maximum wind wave heights using the nonlinear shallow water equation and spectral wave model SWAN (Simulating Waves Nearshore), respectively. Entering the properties of the simulated storm surge, we predict the inundation depth of each 30m mesh area in Osaka Bay using an inundation simulation model based on the $2 \mathrm{D}$ shallow water equation ${ }^{46,47}$ We select the largest inundation areas of the four typhoons because the fifth typhoon does not cause any inundation under the current protection level in the target area. Thus, we have the worst four projections of inundation depth over 200 years for each mesh. It can be roughly interpreted that the first, second, third, and fourth worst inundation results are projected to occur with return periods of once in $200,100,70$, and 50 years. We consider it as a PDF of storm surge inundation risk. To explore ambiguity, the process from typhoon simulation to inundation simulation is repeated 25 times to obtain 25 PDFs of storm surge inundation risk in each mesh. Finally, the simulated inundation depths of $30 \mathrm{~m}$ meshes are averaged over each zip-code area. The average and worst projections of the inundation risk with the current dike level in 
each zip-code area are shown in Fig. 1.

Elicitation of the homeowners' preferences: The stated preference method. We estimate households' preferences for full protection from storm surge risks under ambiguity by using the stated preference method, which asks the respondents to make hypothetical choices in controlled experiments. ${ }^{53,54}$ The current study is the first attempt to estimate households' preferences under ambiguity by coupling GSTCM and a stated preference experiment. Our stated preference survey includes a choice experiment in which the respondents were asked to choose whether to buy a hypothetical insurance that covers all losses of their houses from storm surges under multiple projections of the inundation risk as ambiguity. Using the choice experiment data, we estimate a decision model to calculate the risk and ambiguity premiums.

Decision model under ambiguity. Although a number of decision models under ambiguity have been developed, ${ }^{55-58}$ no model is widely accepted. We use a LDC model to address with ambiguity of storm surge risks because this model is applied to design robust strategies for dealing with the uncertainty of climate change..$^{31,48-50}$ The LDC model can be interpreted as a special case of a neoadditive model of Chateauneuf et al., ${ }^{59}$ which includes two popular decision models under ambiguity: the Choquet expected utility model ${ }^{60}$ and the $\alpha$-maximin expected utility model. ${ }^{61}$ In our context, the LDC model is given by:

$$
V(P)=\alpha E_{p_{A}}(u)+(1-\alpha) E_{p_{W}}(u)
$$


where $u$ is the utility function, $P$ is a set of probability distribution functions, and $p_{A}$ and $p_{W} \in P$ are the average and worst probability distribution functions, respectively. The parameter $\alpha \in[0,1]$ represents the degree of confidence in the expected utility based on the average projection. In our context, $P$ is the set of multiple projections of the storm surge inundation risk, and $p_{A}$ and $p_{W}$ are the average and worst projections, respectively. Accordingly, $E_{p A}(u)$ and $E_{p_{W}}(u)$ are expected utilities with $p_{A}$ and $p_{W}$, respectively. $V(P)$ is the expected utility with the LDC model of the homeowner facing $P$.

To design choice experiments in the stated preference survey, we consider the situation that a household choose to buy an insurance covering all losses from a storm surge. Household $i$ faces multiple projections of storm surge inundation risks in his/her house. House damage from storm surge is divided into four categories; "no flooding," "flooding under floor," "flooding on floor," "house submerged." The average and worst projections of storm surge inundation risks for household $i$ are given as:

$$
\begin{gathered}
p_{i A}=\left(p_{i A 0}, m_{i} ; p_{i A 1}, m_{i 1} ; p_{i A 2}, m_{i 2} ; p_{i A 3}, m_{i 3}\right) \\
p_{i W}=\left(p_{i W 0}, m_{i} ; p_{i W 1}, m_{i 1} ; p_{i W 2}, m_{i 2} ; p_{i W 3}, m_{i 3}\right)
\end{gathered}
$$


where $p_{i A 0}, p_{i A 1}, p_{i A 2}$, and $p_{i A 3}$ are the average probabilities of "no flooding," "flooding under floor," "flooding on floor," "house submerged," respectively. Similarly, $p_{i W 0}, p_{i W 1}, p_{i W 2}$, and $p_{i W 3}$ are the worst probabilities. The house value of household $i$ is $m_{i}$, which becomes $m_{i 1}, m_{i 2}$, and $m_{i 3}$ when it gets "flooding under floor," "flooding on floor," "house submerged," respectively.

The econometric model is as follows. The LDC expected utility without insurance can be written as:

$$
V_{i 1}=\alpha E_{p_{i A}}(u)+(1-\alpha) E_{p_{i W}}(u)
$$

where $u$ is the CRRA utility function with coefficient $r$ as follows:

$$
u(m)=\frac{m^{1-r}}{1-r}
$$

The LDC expected utility with insurance at cost of $m C_{i}$ is given as:

$$
V_{i 2}=u\left(m-m C_{i}\right)
$$

where $C_{i}$ is the insurance fare rate such that $m C_{i}$ is a household's payment for buying an insurance. 
A household chooses to buy insurance if the following inequality holds:

$$
V_{i 1}+\varepsilon_{1}<V_{i 2}+\varepsilon_{2}
$$

where $\varepsilon_{1}$ and $\varepsilon_{2}$ are random components of utilities and $\epsilon=\varepsilon_{1}-\varepsilon_{2} \sim N(0,1)$. The probability of buying insurance can be written as:

$$
\operatorname{Prob}\left(V_{i 1}+\varepsilon_{2}<V_{i 2}+\varepsilon_{1}\right)=\operatorname{Prob}\left(\epsilon<V_{i 2}-V_{i 1}\right)=\Phi\left(V_{i 2}-V_{i 1}\right),
$$

where $\Phi$ is the standard normal distribution function. Thus, the log-likelihood to be maximized is written as:

$$
\ln L(\alpha, r)=\sum_{i=1}^{n}\left[d_{i} \ln \Phi\left(V_{i 2}-V_{i 1}\right)+\left(1-d_{i}\right) \ln \left\{1-\Phi\left(V_{i 2}-V_{i 1}\right)\right\}\right]
$$

where $d_{i}$ is a dummy variable taking a value of 1 if household $i$ chooses to buy the insurance and 0 otherwise, and $n$ is the number of respondents.

Estimation of expected loss, risk premium, and ambiguity premium. Based on the LDC model, the willingness to pay of household $i$ for the full protection of insurance policy $\left(W T P_{i}\right)$ is calculated as follows: 


$$
W T P_{i}=m_{i}-u^{-1}\left(\alpha E_{p_{i A}}(u)+(1-\alpha) E_{p_{i W}}(u)\right)
$$

where $u^{-1}$ is an inverse function of $u$. The expected loss, risk premium, and ambiguity premium are defined by the following equations. The expected loss, $E L_{i}$ is defined as the full asset value, $m_{i}$, minus the expected value, $E V_{i}$, with the average projection of storm surge risk as:

$$
E L_{i}=m_{i}-E V_{i}
$$

where $E V_{i}=p_{i A 0} m_{i}+p_{i A 1} m_{i 1}+p_{i A 2} m_{i 2}+p_{i A 3} m_{i 3}$. The certainty equivalent for risk $C E_{i}^{r i s k}$ is a certain value that is equally attractive to the household's asset facing storm surge risks in the average projection and can be written as follows:

$$
C E_{i}^{r i s k}=u^{-1}\left(E_{p_{i A}}(u)\right)
$$

The risk premium, $R P_{i}$, is defined as the expected value minus the certainty equivalent for risk.

$$
R P_{i}=E V_{i}-C E_{i}^{r i s k}
$$


There is no widely accepted definition of the ambiguity premium, while the expected loss and risk premium are clearly defined. However, we follow the definition proposed by Cubit, van de Kuilen, and Mukerji, ${ }^{62}$ as it can be applied to any decision model. By an analogous notion to certainty equivalent for risk, we consider the certainty equivalent for ambiguity $C E_{i}^{a m b}$. It is a certain value that is equally attractive to the household's asset facing storm surge risks under ambiguity and can be written as follows:

$$
C E_{i}^{a m b}=u^{-1}\left(\alpha E_{p_{i A}}(u)+(1-\alpha) E_{p_{i W}}(u)\right)
$$

The ambiguity premium is defined as certainty equivalent for risk minus certainty equivalent for ambiguity. ${ }^{62}$

$$
A P_{i}=C E_{i}^{r i s k}-C E_{i}^{a m b}
$$

Note that the following equation holds because $C E_{i}^{a m b}$ is equivalent to $m_{i}-W T P_{i} .-$

$$
W T P_{i}=E L_{i}+R P_{i}+A P_{i}
$$

Finally, these values are calculated by using the estimated econometric model of the LDC model. 
Experimental design of web survey. We conducted the choice experiments on households'

preferences for purchasing the hypothetical insurance through a web survey. The steps are as follows:

(1) Explain the impact of disasters on daily life and past damages due to storm surge disasters and inundation (abstracted from the leaflet by the Japanese government).

(2) Ask respondents about the estimated values of their house and furniture. These data were used in the latter part of the survey.

(3) Explain that projections of storm surge inundation risks inevitably include ambiguity and that 25 PDFs of storm surge inundation risks were projected as ambiguity.

(4) Explain that the damage to house from storm surge inundation is classified into four categories according to the inundation depth: "no flooding," "flooding under floor," "flooding on floor," and "house submerged" when the inundation depth is less than $0.01 \mathrm{~m}, 0.01 \mathrm{~m}-0.5 \mathrm{~m}, 0.5 \mathrm{~m}-$ $2.0 \mathrm{~m}$ and $2.0 \mathrm{~m}$ or over, respectively.

(5) Two projections of storm surge inundation risks were randomly chosen from a set of five inundation projections that are typical in the target area (Fig. S4). The more serious one was set as the worst projection and the other was set as the average projection. Then these projections were presented to the respondents.

(6) When "flooding under floor," "flooding on floor," and "house submerged" occur due to storm surge floods, we assume $1 \%, 50 \%$, and $100 \%$ loss of the households' assets (house and furniture) value as responded in step (2). The amount of economic loss due to storm surge 
inundation was automatically calculated on the web system and presented to the respondents.

(7) To evaluate the economic value that completely eliminates the risk of damage due to storm surge flooding, respondents were asked whether or not to buy a hypothetical insurance that fully compensates them for the storm surge damages (Fig.2). The question was as follows: "Suppose that the government sells a new insurance, which covers all losses due to storm surge floods with full compensation for house restoring cost and household assets, and that the insurance will be contracted once in a year, would you like to buy this new insurance policy with the annual fee of XXX yen?" The amount of insurance fee (XXX yen/year) was automatically calculated and presented to the respondents according to the following formula: their estimated household asset value $\times 0.001 \%, 0.005 \%, 0.01 \%, 0.05 \%, 0.1 \%, 0.5 \%$, and $1 \%$ (one of these amounts was randomly chosen and presented to the respondent in the web system).

(8) We estimated the LDC model using the survey data after excluding "protest responses." 54 The protest responses were obtained from the respondents who chose not to buy the hypothetical insurance due to the following two reasons: "I cannot understand the question" and "I cannot accept the hypothetical scenarios." The number of protest responses is 340 (34\%). As a result, the effective number of observations is 660 .

Outline of survey attributes. The respondents of the web surveys were recruited from 1.9 million panel members registered with Cross Marketing, a Japanese company. The web survey was conducted with 1,000 households who responded that they live at an altitude of $5 \mathrm{~m}$ or less among the 
detached houses in Osaka Bay. This survey was conducted from December 16 to December 22 in 2016. Table S1 shows the means and standard deviations of the socioeconomic attributes of the respondents.

\section{Data availability}

The data that support the findings of this study are available online at https://rive.google.com/drive/u/1/folders/1XHIMFZuCATM0mtpMsQ4-mzwATEiaKQiH

\section{References}

51. Emanuel, K., Ravela, S., Vivant, E., \& Risi, C. A statistical deterministic approach to hurricane risk assessment. Bull. Amer. Meteor. Soc. 87, 299-314 (2006). https://doi.org/10.1175/BAMS-873-299

52. Rumpf, J., Weindl, H., Höppe, P., Rauch, E., \& Schmidt, V. Stochastic modelling of tropical cyclone tracks. Math. Methods Oper. Res. 66, 475-490 (2007). https://doi.org/10.1007/s00186007-0168-7

53. Louviere, J. J., Hensher, D. A., \& Swait, J. D. Stated Choice Methods: Analysis and Applications $1^{\text {st }}$ Edition (Cambridge University Press, $1^{\text {st }}$ edition, Cambridge, 2000).

54. Johnston, R. J. et al. Contemporary guidance for stated preference studies. J. Assoc. Environ. Resour. Econ. 4, 319-405 (2017). https://doi.org/10.1086/691697

55. Ryan, M. J. Generalizations of SEU: A geometric tour of some non-standard models. Oxford Economic Papers 61, 327-354 (2009). https://doi.org/10.1093/oep/gpn027 
56. Lempert, R. J., Groves, D. G., Popper, S. W., \& Bankes, S. C. A general, analytic method for generating robust strategies and narrative scenarios. Manag. Sci. 52, 514-528 (2006). https://doi.org/10.1287/mnsc. 1050.0472

57. Machina, M. J. \& Siniscalchi, M. Ambiguity and ambiguity aversion. In M. J. Machina \& W. K. Viscusi (Eds.). Handbook of the economics of risk and uncertainty 1, 729-807 (2014). https://doi.org/10.1016/B978-0-444-53685-3.00013-1

58. Gilboa, I. \& Marinacci, M. Ambiguity and the Bayesian paradigm. In Readings in formal epistemology. Springer Graduate Texts in Philosophy 1, 385-439 (2016) https://doi.org/10.1007/978-3-319-20451-2_21

59. Chateauneuf, A., Eichberger, J., \& Grant, S. Choice under uncertainty with the best and worst in mind: Neo-additive capacities. J. Econ. Theory 137, 538-567 (2007). https://doi.org/10.1016/j.jet.2007.01.017

60. Schmeidler, D. Subjective probability and expected utility without additivity. Econometrica 57, 571-587 (1989). https://doi.org/10.2307/1911053

61. Ghirardato, P., Maccheroni, F., \& Marinacci, M. Differentiating ambiguity and ambiguity attitude. J. Econ. Theory 118, 133-173 (2004). https://doi.org/10.1016/j.jet.2003.12.004

62. Cubit, R., van de Kulien G., \& Mukerji, S. The strength of sensitivity to ambiguity. Dec. Theory 85, 275-302 (2018). https://doi.org/10.1007/s11238-018-9657-9 
a. Average projection

Current dike level

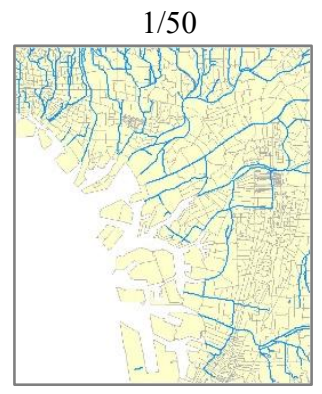

$3 / 200$
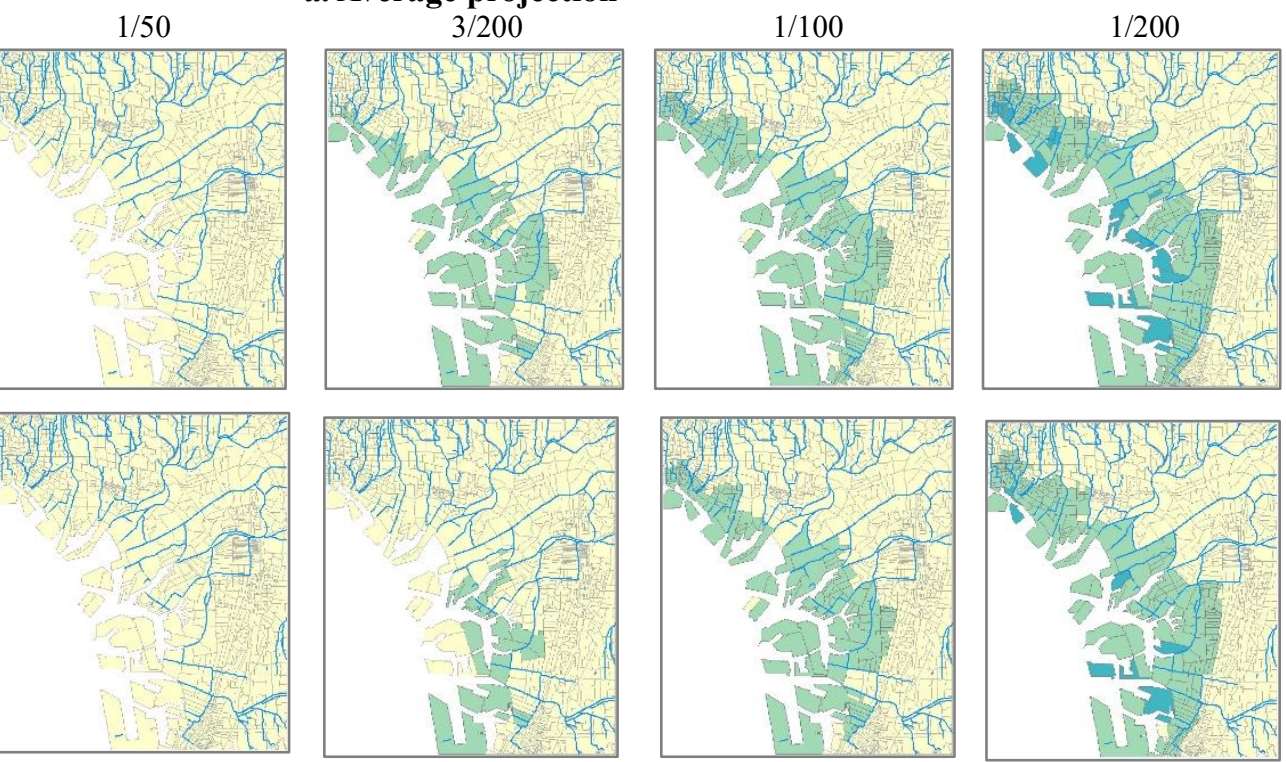

Dike rising by $0.5 \mathrm{~m}$

Dike rising by $1.0 \mathrm{~m}$
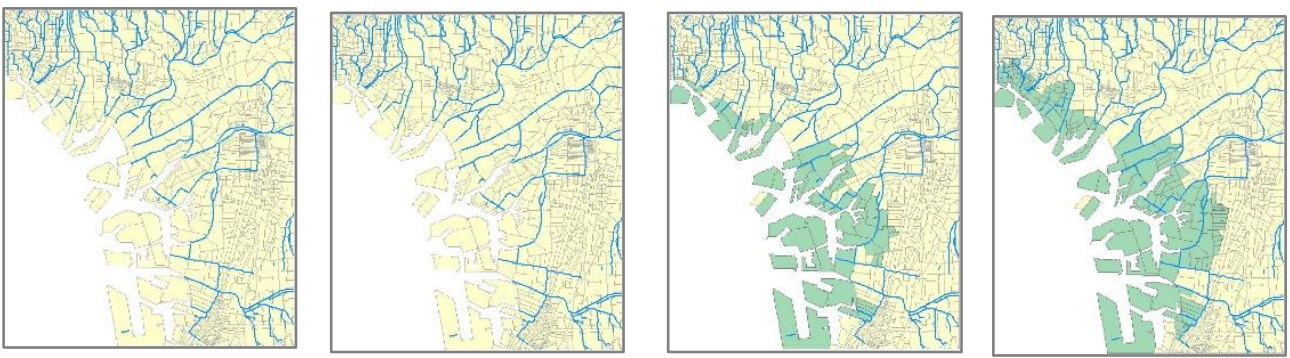

Dike rising by $1.5 \mathrm{~m}$
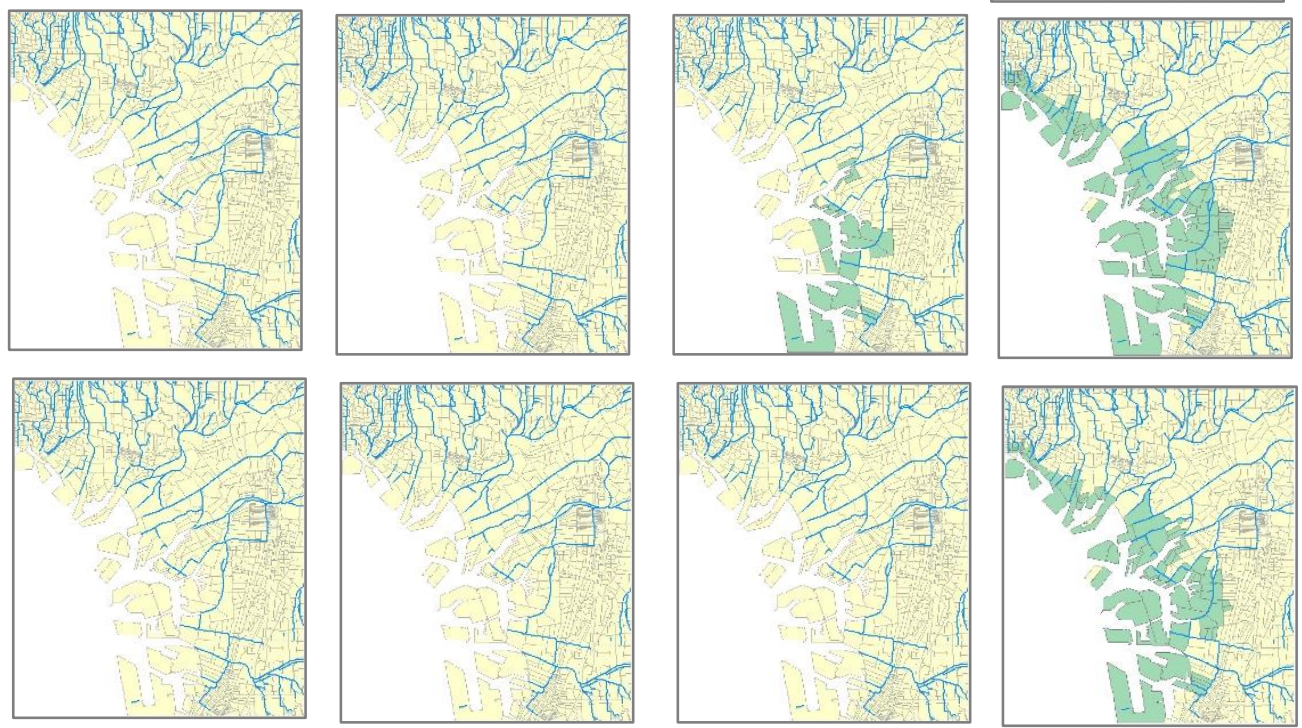
Rive 


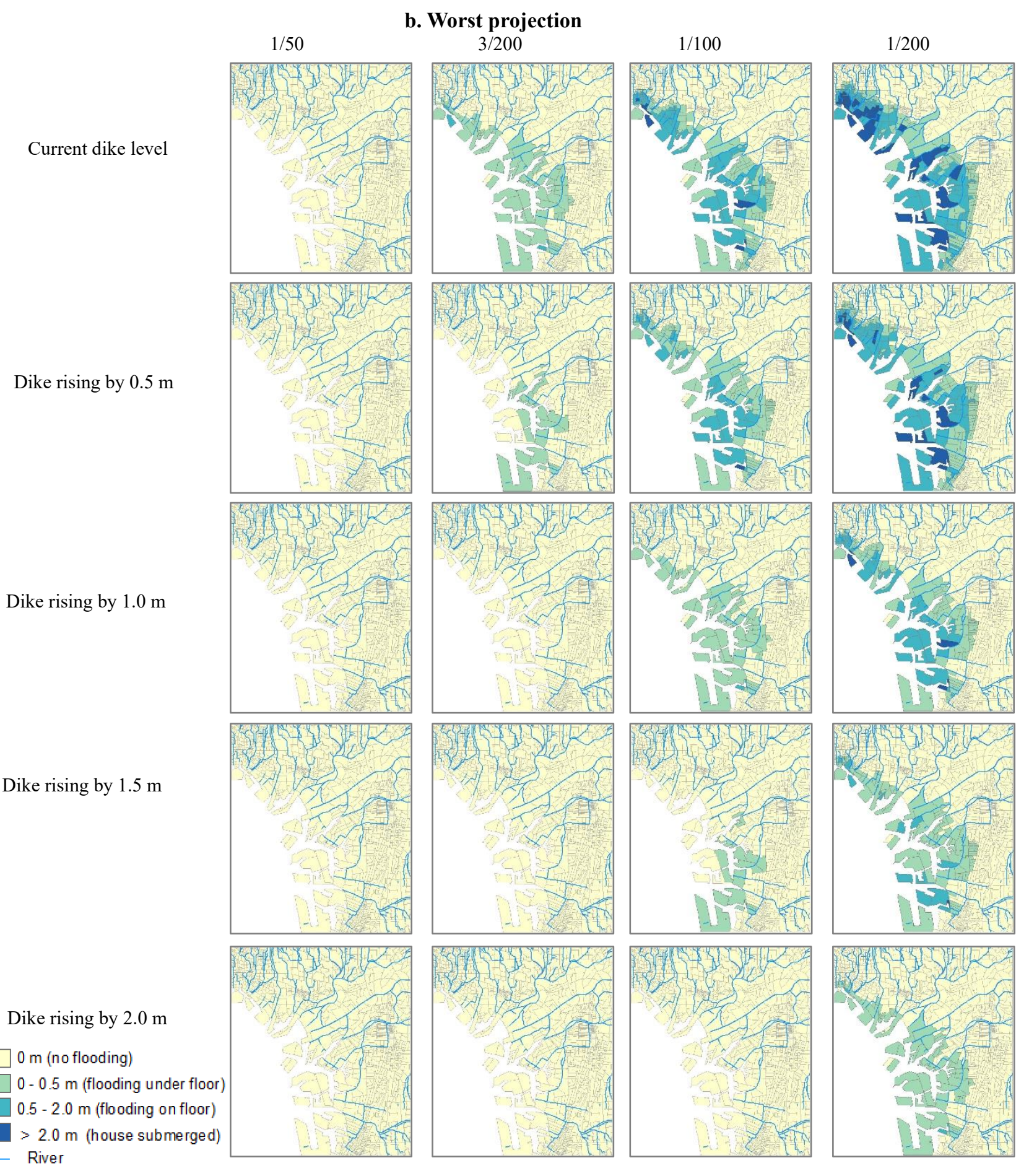

Fig. 1 | Storm surge inundation risks of a. average projection and b. worst projection by current and dike rising levels. $1 / 50,3 / 200,1 / 100$, and $1 / 200$ denote once in $50,67,100$ and 200 years. Within the range of $22.23 \mathrm{~km}$ long by 19.32 $\mathrm{km}$ wide along the coastal areas of Osaka Bay extending between Osaka prefecture and Hyogo prefecture including Osaka city, the third largest city in Japan (Fig. S1). They are mainly flat lowlands surrounded by four main river systems namely Yodo, Kanzaki, Yamato, and Neya rivers. According to the Census Mesh Data (the Statistics Bureau of Japan, 2015), it has 1.63 million households with 3.30 million people, of which, our target respondents represent $25 \%$ of the households. 
Average projection In the average one among 25 projections of inundation risk from typhoon simulation, the inundation risk of your house was projected as the following figure.

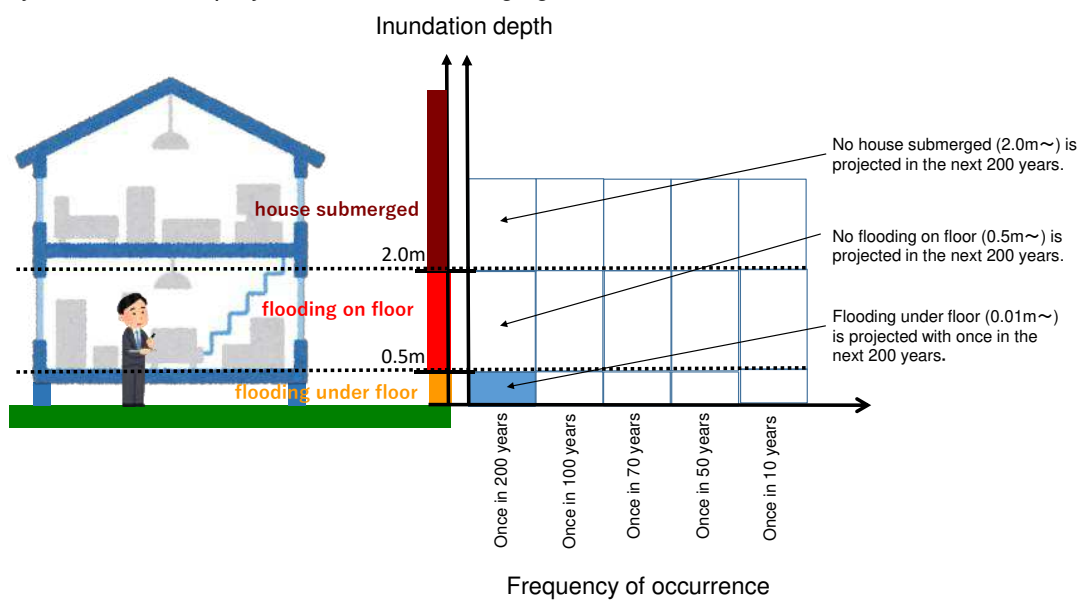

Worst projection

In the worst one among 25 projections of inundation risk from typhoon simulation, the inundation risk of your house was projected as the following figure.

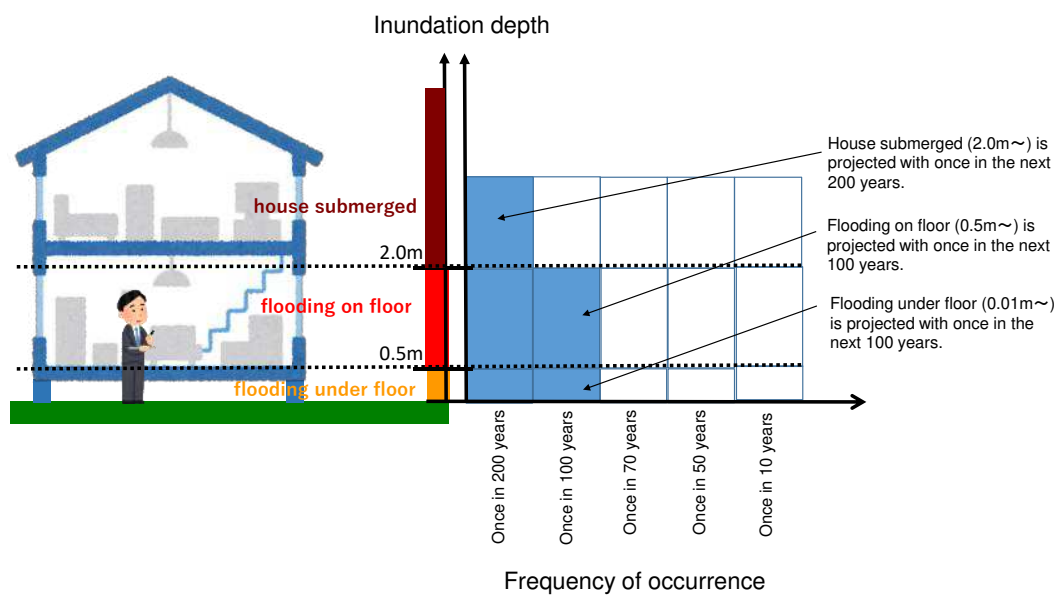

Scenario Assumption.

Frequency of occurrence

- If your house gets flooded under floor (inundation depth is below $0.5 \mathrm{~m}$ ) from storm surge, your economic loss is AAA yen ( $1 \%$ of your asset value).

- If your house gets flooded on floor (inundation depth is $0.5 \mathrm{~m}-2.0 \mathrm{~m}$ ) from storm surge, your economic loss is BBB yen ( $50 \%$ of your asset value).

- If your house gets submerged (inundation depth is over $2.0 \mathrm{~m}$ ) from storm surge, your economic loss is CCC yen (100\% of your asset value).

- You do not have any insurance for compensating economic loss from storm surge.

Suppose that the government sells a new insurance which covers all losses due to storm surge floods with full compensation of house restoring cost and households assets back, and that the insurance will be contracted once in a year. Do you like to buy this new insurance policy with the annual fee of XXX yen?

- Yes, l'd like to buy the insurance with annual fee of XXX yen.

- No, l'd not like to buy the insurance.

Why did you chose not to buy the insurance? Please choose one of the following options as your reason.

- The insurance fee is too expensive

- I can not understand the question
- I can not accept the hypothetical scenarios

- Other reasons (

Fig. 2 Ambiguity or multiple projections of the storm surge risks (average and worst projections) were embedded into the homeowners' preferences during the survey. This also shows an example of scenarios for choice experiment and the key parts of the questionnaire. Economic loss of AAA, BBB, and CCC were calculated with $1 \%, 50 \%$, and $100 \%$ of the respondent's asset value. XXX were randomly chosen to the respondents based on the given asset value: their estimated household asset value $\times 0.001 \%, 0.005 \%, 0.01 \%, 0.05 \%, 0.1 \%, 0.5 \%$, and $1 \%$. The amounts of AAA, BBB, CCC, and XXX were automatically calculated in the web survey system. 
WTP

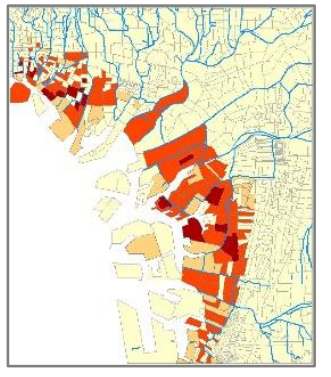

Expected Loss Reduction

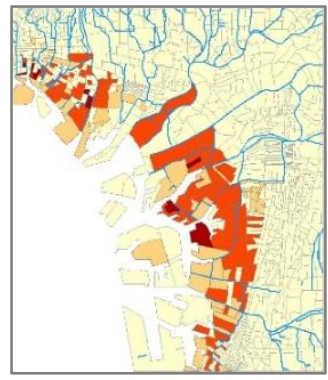

Full protection

from 0 to $0.5 \mathrm{~m}$
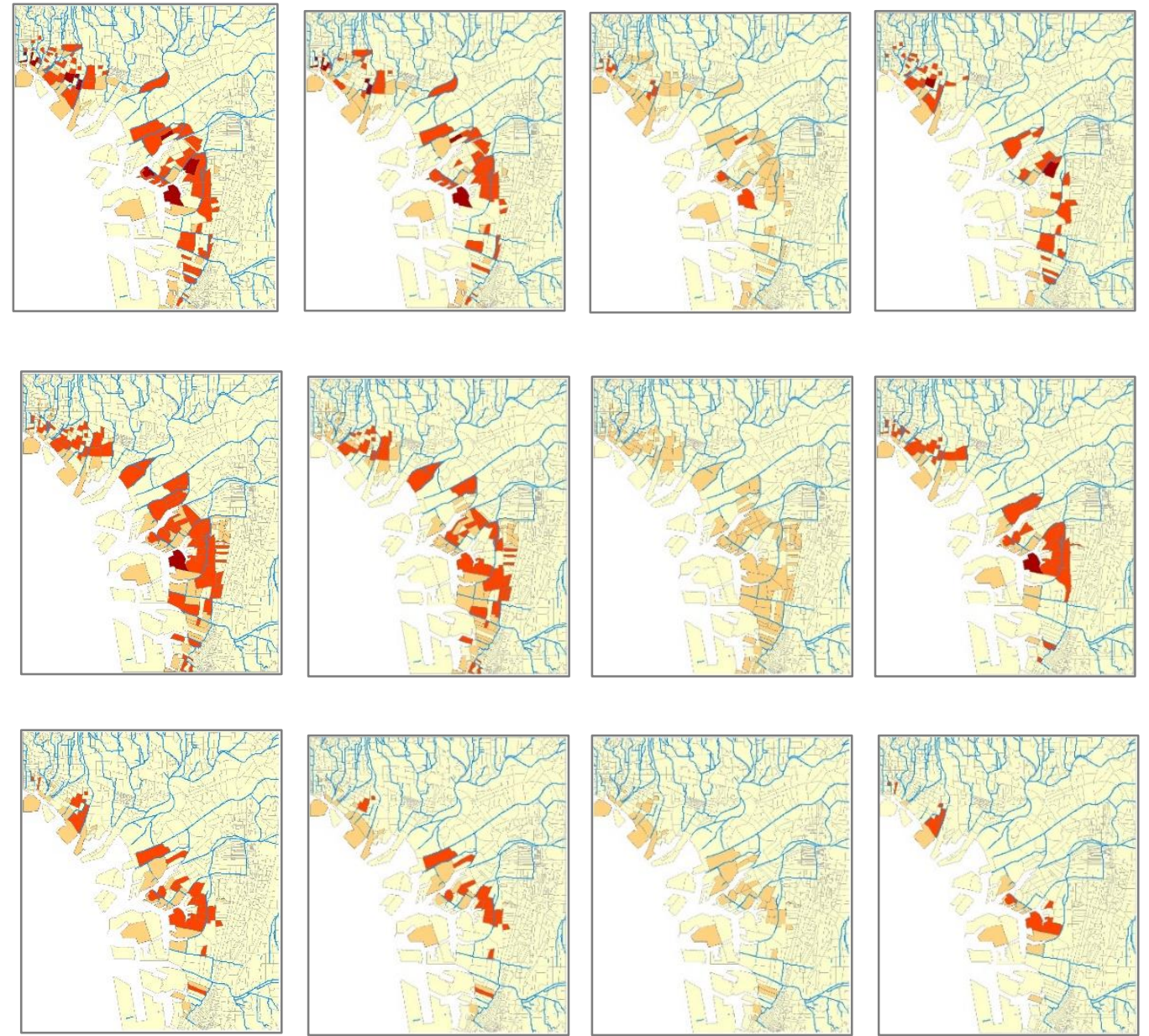

Dike rising

from 1.5 to $2.0 \mathrm{~m}$
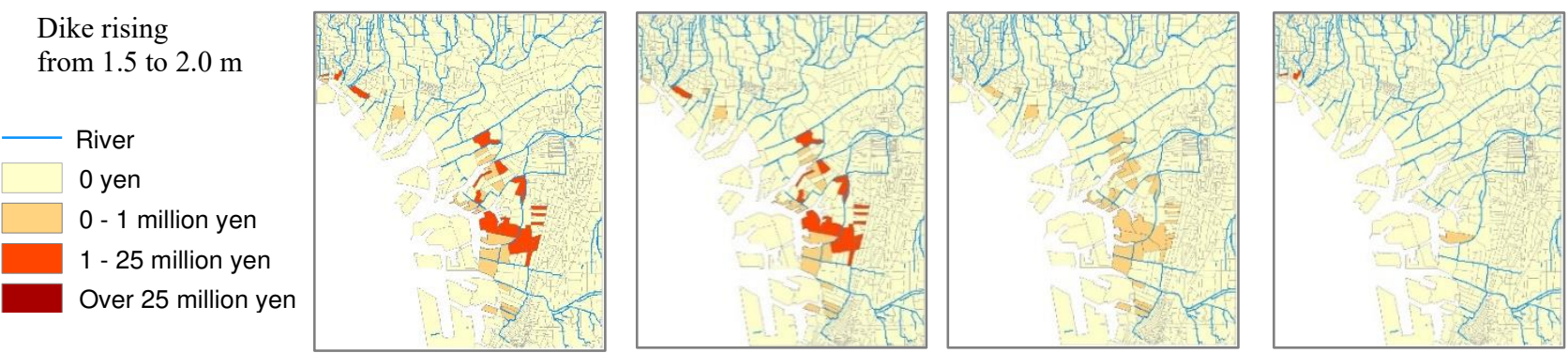

Fig. 3 | Geographical distributions of the expected loss reduction, risk premium, and ambiguity premium for full protection from storm surge risks and each step of dike rising by $0.5 \mathrm{~m}$ from 0 to $2.0 \mathrm{~m}$
Ambiguity Premium

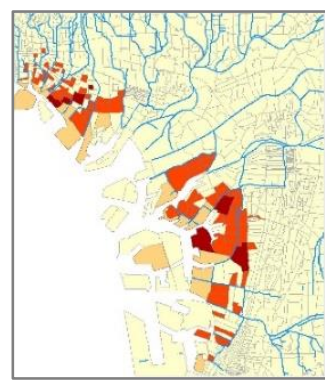

Dike rising from 1.0 to $1.5 \mathrm{~m}$
Dike rising

from 0.5 to $1.0 \mathrm{~m}$

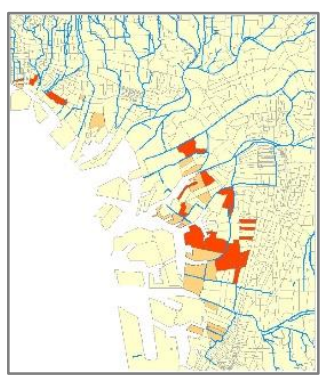

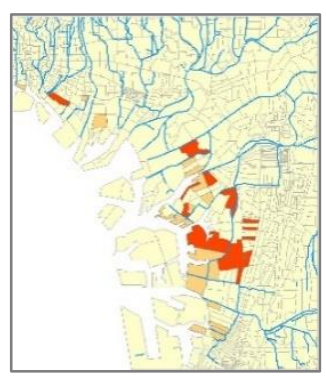

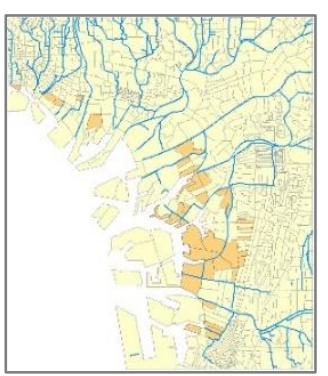


Table 1|Estimated parameters of LDC model: confidence of degree, $\alpha$ and CRRA coefficient, $r$

\begin{tabular}{|c|c|c|c|c|}
\hline & \multicolumn{2}{|c|}{ Model 1} & \multicolumn{2}{|c|}{ Model 2} \\
\hline & Coefficient & Standard Error & Coefficient & Standard Error \\
\hline \multicolumn{5}{|c|}{$\alpha:$ confidence of degree } \\
\hline Constant & $0.9049 * *$ & 0.0385 & $0.9839 * *$ & 0.2625 \\
\hline Age & & & 0.0005 & 0.0035 \\
\hline Gender & & & 0.0640 & 0.0729 \\
\hline Family size & & & -0.0415 & 0.0332 \\
\hline Education & & & -0.0086 & 0.0817 \\
\hline \multicolumn{5}{|l|}{$r$ : risk attitude } \\
\hline Constant & $0.3764 * *$ & 0.0123 & $0.4481 * *$ & 0.0775 \\
\hline Age & & & -0.0024 & 0.0013 \\
\hline Gender & & & -0.0383 & 0.0313 \\
\hline Family size & & & 0.0125 & 0.0090 \\
\hline Education & & & 0.0380 & 0.0276 \\
\hline Sample size & \multicolumn{2}{|c|}{660} & \multicolumn{2}{|c|}{660} \\
\hline Log likelihood & \multicolumn{2}{|c|}{-391.5} & \multicolumn{2}{|c|}{-385.2} \\
\hline Pseudo R2 & \multicolumn{2}{|c|}{0.134} & \multicolumn{2}{|c|}{0.148} \\
\hline
\end{tabular}

“**” represent statistical significance at $1 \%$.

Pseudo $R^{2}=1-L 1 / L 0$ where $L 0$ and $L 1$ represent loglikelihoods of the models with and without the constraint that all parameters are zero.

Table 2|Estimated reduction of expected loss, risk premium and ambiguity premium for full protection and dike rising levels. Parentheses indicate ratios of risk premium, ambiguity premium, and total economic value (WTP) of expected loss reduction.

\begin{tabular}{|c|c|c|c|c|c|c|}
\hline \multirow{2}{*}{ Value (million yen) } & \multirow{2}{*}{$\begin{array}{c}\text { Benefit of } \\
\text { full protection* }\end{array}$} & \multirow{2}{*}{$\begin{array}{c}\text { Value of } 2.0 \mathrm{~m} \\
\text { dike rising }\end{array}$} & \multicolumn{4}{|c|}{ Value of additional dike rising } \\
\hline & & & 0 to $0.5 \mathrm{~m}$ & 0.5 to $1.0 \mathrm{~m}$ & 1.0 to $1.5 \mathrm{~m}$ & 1.5 to $2.0 \mathrm{~m}$ \\
\hline Reduction of expected loss & 821 & 769 & 581 & 110 & 41 & 36 \\
\hline Risk premium & $\begin{array}{c}65 \\
(0.08)\end{array}$ & $\begin{array}{c}65 \\
(0.08)\end{array}$ & $\begin{array}{c}64 \\
(0.11)\end{array}$ & $\begin{array}{c}1 \\
(0.01)\end{array}$ & $\begin{array}{c}0 \\
(0.00)\end{array}$ & $\begin{array}{c}0 \\
(0.00)\end{array}$ \\
\hline Ambiguity premium & $\begin{array}{c}849 \\
(1.03)\end{array}$ & $\begin{array}{c}848 \\
(1.10)\end{array}$ & $\begin{array}{c}395 \\
(0.68)\end{array}$ & $\begin{array}{c}390 \\
(3.53)\end{array}$ & $\begin{array}{c}55 \\
(1.33)\end{array}$ & $\begin{array}{c}9 \\
(0.25)\end{array}$ \\
\hline Total economic value (WTP) & $\begin{array}{l}1,734 \\
(2.11) \\
\end{array}$ & $\begin{array}{l}1,682 \\
(2.19)\end{array}$ & $\begin{array}{r}1,040 \\
(1.79) \\
\end{array}$ & $\begin{array}{r}500 \\
(4.54) \\
\end{array}$ & $\begin{array}{c}96 \\
(2.33) \\
\end{array}$ & $\begin{array}{c}46 \\
(1.26) \\
\end{array}$ \\
\hline
\end{tabular}

* Value of eliminating all damage from storm surge with current dike level 


\section{Supplementary Files}

This is a list of supplementary files associated with this preprint. Click to download.

- StormNCC20210924Suppsubmit.docx 